\title{
Atık Andezit Tozu ve Uçucu Küllerin Betonda Kullanımının Karşılaştırılması
}

\author{
Hakan Ceylan ${ }^{1 *}$, Metin Davraz ${ }^{2}$ \\ ${ }^{1}$ Isparta Uygulamalı Bilimler Üniversitesi, Teknik Bilimler MYO, Inşaat Bölümü, Batı Kampüs, Isparta. ORCiD: 0000-0001-8099-9819 \\ ${ }^{2}$ Isparta Uygulamalı Bilimler Üniversitesi, Senirkent MYO, Inşaat Bölümü, Senirkent, Isparta. 0RCID: 0000-0002-6069-7802
}

\section{Özet}

Türkiye'de andezit tașı inșaat mühendisliği ve mimari uygulamalarda yaygın olarak kullanılmaktadır. Andezit tașının madencilik yöntemleriyle üretimi, kesilmesi ve cilalanması büyük miktarda atık oluşumuna neden olmaktadır. Bunların bir kısmı ocak ve fabrikadan çıkan iri parçalı atıklardır. Bir kısmı ise fabrikada kesim sırasında çıkan toz atıklardır. Bu atıklar değerlendirilmeden atılmaktadır. Andezit temel bileşen olarak $\mathrm{SiO}_{2}$ içerir, bu yüzden andezit tozları puzolanik özellik gösterir ve betonda mineral katkı olarak kullanılabilir. Bu çalıșmada andezit atık tozlarının betonda mineral katkı olarak kullanılması, F sınıfı uçucu küller ile karşılaştırılmıştır. Mineral katkıların farklı yer değiştirme seviyelerindeki durumunu belirlemek için, farklı çimento dozajlarında beton örnekleri hazırlanarak 28 ve 90 günde beton basınç dayanımları test edilmiştir. C40/50 dayanım sinıfi için, 28 ve 90 günlük kür yaşlarında atık andezit tozlarının en uygun yer değiştirme oranı \%10 olarak belirlenmişstir. Çalışmadan elde edilen bulgulara göre atık andezit tozlarının uçucu küller gibi betonda mineral katkı olarak kullanılabileceğini göstermektedir. Mineral katkı olarak en ideal yer değiștirme oranlarında andezit kullanımı durumunda, C40/50 betonunda yaklașık $20 \mathrm{~kg}$, C55/67 betonunda 46 kg, C70/85 betonunda $52 \mathrm{~kg}$ çimento tasarrufu sağlanabilir.

$\underline{\text { Anahtar Sözcükler }}$

Andezit Toz Atığı, Uçucu Kül, Basınç Dayanımı, Kür Süresi

\section{The Comparison of Using Andesite Waste Powder and Fly Ash in Concrete}

\begin{abstract}
Andesite stone is widely used in civil engineering and architectural applications in Turkey. The production, cutting and polishing of the andesite stone by mining methods causes a large amount of waste. Some of them are big particular waste that is taken off pit and factories. And the others are powder waste derived during cutting in factories. These are wasted and not reclaimed. Andesite contains $\mathrm{SiO}_{2}$ as the main component. Therefore, andesite may have pozzolanicity and thus may be used as mineral additive in concrete. In this study the usage of andesite waste powder as mineral additive in concrete is compared with $F$ type fly ashes. In order to estimate the status of mineral additives in various replacement levels; the 28 and 90 days compressive strengths of concrete specimens were tested by preparing concrete specimens in different cement dosages. For C40/50 strength class, the optimum replacement rate of andesite waste powder was determined as 10\% at curing ages of 28 and 90 days. The results of this study show that andesite waste powder can be used as mineral additive in concrete such as fly ash. The usage of andesite waste powder as a mineral additive at the optimal replacement ratios can achieve savings of, $20 \mathrm{~kg}$ cement for C40/50, $46 \mathrm{~kg}$ of cement for C55/67, and $52 \mathrm{~kg}$ of cement for C70/85.
\end{abstract}

\section{$\underline{\text { Keywords }}$}

Andesite Waste Powder, Fly Ash, Compressive Strength, Curing Period

\section{Giriş}

Türkiye, Portekiz, İspanya, İtalya, Yunanistan, İran ve Pakistan’la beraber doğal taş üretiminde önemli bir yere sahiptir. Türkiye, Dünya'da doğal taş üretiminin \%40'1na sahiptir. Türkiye'de yılda 7 milyon ton doğal taş üretilir ve bu üretimin \%75'i yaklaşık 5000 tesiste işlenir. Dekoratif amaçlar doğal taş üretiminde kesme, cilalama gibi işlemlerde yan ürün olarak toz ve agrega oluşur (Karakuş 2011; Alyamaç ve İnce 2009; Gencel vd. 2012). Geniş ölçekli andezit üretiminde dikkate değer miktarda atık malzeme oluşturmaktadır; madencilik, işleme ve cilalama aşamalarında neredeyse andezitin \%70'i atıktır (Soğancıoğlu vd. 2013). Doğal taşlar oluşum özelliklerine göre metamorfik (mermer, gnays vd.), sedimanter (kireçtaşı, traverten vd.) ve magmatik (granit, gabro, bazalt, andezit vd.) olarak sınıflandırılır. Andezit magmatik kayaçların bir alt grubunu oluşturan volkanik kayaç grupları içerisinde sınıflandırılır. Andezit Türkiye'de ve dünyanın diğer pek çok bölgesinde çok uzun süredir özellikle kaldırım, parke, kaplama, denizlik, söve yapımı gibi özellikle inşaat mühendisliği ve mimarlık işlerinde kullanılmaktadır (Sarışı1k vd. 2011). 
Puzolanik aktivite, suyun varlığında sönmüş kireçle tepkiyen puzolanların bağlayıcılık kapasitesi olarak tanımlanır. Puzolanik kapasitenin oranı puzolanların özgül yüzey alanına, özgün karakteristiklerine, kimyasal bileşenlerine ve aktif faz içeriğine bağlıdır (Erdoğan 2007). Puzolanlar betonda çimentonun bir miktarını azaltan mineral katkılar olarak kullanılır. Hem de direkt olarak çimento üretiminde kullanılabilir. Andezit temel bileşen olarak $\mathrm{SiO}_{2}$ içerir ve bu yüzden andezit atıkları puzolanik aktivite göstermektedirler (ASTM C 125 1994, ASTM C 618 1994).

Son yıllarda beton, harç ve çimentoda farklı puzolanların kullanımıyla ilgili pek çok araştırmacı tarafından çalışmalar yürütülmüştür. Bunlar taş tozu (Almedia vd. 2007a), mermer tozu (Almedia vd. 2007b; Topçu vd. 2009; Alyamaç ve İnce 2009; Corinaldesi vd. 2010; Aruntaş vd. 2010; Belaidi vd. 2012), kireçtaşı tozu, bazalt tozu, yüksek firın cürufu, uçucu kül (Uysal ve Yılmaz 2011; Uysal ve Sümer 2011; Gesoğlu vd. 2012), diatomit, pomza (Ergün 2011; Aydın ve Gül 2007) ve pirinç kabuğu külüdür (Jain 2012). Mineral katkı olarak andezit tozlarıyla yapılmış araştırma sayısı ise çok azdır. Hamidi vd. (2013), farklı çimento türleri kullanarak, doğal ve kalsine edilmiş andezit tozunun etkinlik faktörünü araştırmıştır. Bu çalışmada andezitin harçların dayanımına etkisini belirlemek için, Feret Kanunu uygulamasına dayandırılan bir analiz kullanmıştır. CEM I $42.5 \mathrm{~N}$ tipi çimento için, \%10, 20, 30 ve 40 oranlarında andezit kullanımında, uzun dönemli etkinlik faktörü değerlerini sırasıyla, 0.85, 0.65, 0.65 ve 0.50 bulmuştur (Hamidi vd. 2013).

$\mathrm{Bu}$ çalışmada, atık andezit tozlarının ve karşılaştırmak amacıyla iki farklı uçucu külün puzolanik aktiviteleri araştırılmıştır. Farklı dayanım sınıfı ve kür süreleri için, andezit tozları ve uçucu küllerin üç değişik yer değiştirme oranında dayanım değerleri araştırılmıştır. Sonuçta andezit atık tozlarının bazı yer değiştirme oranlarında F sınıfı uçucu küllere yakın dayanım değerleri sergilediği ve yeterli inceliğe sahip andezit atık tozlarının betonda mineral katkı maddesi olarak kullanılabileceği belirlenmiştir.

\section{Materyal ve Metot}

\subsection{Materyal}

Bu çalışmada bağlayıcı olarak CEM I 42.5 R tipi çimentosu, mineral katkılar olarak andezit atık tozu (AT), Seyitömer uçucu külü (SUK) ve Tunçbilek uçucu külü (TUK) kullanılmıştır. AT Isparta Belediyesi'ne ait Doğal Taş Fabrikası'ndan (ISTEM) sağlanmıştır. Bu fabrikanın atıklarından alınan andezit tozları ögütülerek $0.63 \mu$ 'nun altına elenmiştir. Çimento ve mineral katkılara ait özellikler Tablo 1'de verilmiştir.

Tablo 1: Çimento, AT, SUK ve TUK'nün kimyasal ve fiziksel özellikleri

\begin{tabular}{|c|c|c|c|c|}
\hline \multirow{2}{*}{$\begin{array}{c}\text { Kimyasal } \\
\text { Bileșen }\end{array}$} & Çimento & AT & SUK & TUK \\
\cline { 2 - 5 } & $(\boldsymbol{\%})$ & $(\boldsymbol{\%})$ & $(\boldsymbol{\%})$ & $(\boldsymbol{\%})$ \\
\hline $\mathrm{SiO}_{2}$ & 20.74 & 56.34 & 54.81 & 58.28 \\
\hline $\mathrm{Al}_{2} \mathrm{O}_{3}$ & 4.12 & 18.21 & 20.18 & 17.67 \\
\hline $\mathrm{Fe}_{2} \mathrm{O}_{3}$ & 3.56 & 5.61 & 9.52 & 12.92 \\
\hline $\mathrm{MgO}$ & 1.59 & 1.62 & 4.65 & 1.76 \\
\hline $\mathrm{CaO}$ & 64.18 & 4.45 & 5.08 & 4.46 \\
\hline $\mathrm{Na}_{2} \mathrm{O}$ & 0.63 & 3.85 & 0.71 & 0.71 \\
\hline $\mathrm{K}_{2} \mathrm{O}$ & 0.72 & 2.90 & 0.66 & 0.31 \\
\hline $\mathrm{TiO}_{2}$ & - & 0.52 & - & 1.23 \\
\hline $\mathrm{SO}_{3}$ & 2.56 & 0.19 & 0.72 & 58.28 \\
\hline $\mathrm{K}_{1 z d r m a ~ K a y b 1}$ & 2.69 & 3.38 & 3.04 & 2.38 \\
\hline Fiziksel & & & & \\
\hline Özgül Ağılık & 3.12 & 2.66 & 2.23 & 2.13 \\
\hline İncelik (cm $\left.{ }^{2} / g\right)$ & 3120 & 5790 & 3590 & 3810 \\
\hline
\end{tabular}

Çalışmada andezit atık tozunun mineral katkı olarak kullanımını karşılaştırmak için iki farklı uçucu kül kullanılmıştır. Betonda mineral katkı olarak kullanılan uçucu küller ASTM C 618'de sınıflandırılmıştır (ASTM C 618 1994). Toplamda üç majör oksit $\left(\mathrm{SiO}_{2}+\mathrm{Al}_{2} \mathrm{O}_{3}+\mathrm{Fe}_{2} \mathrm{O}_{3}\right) \quad \mathrm{C}$ sınıfı için \%50'den ve $\mathrm{F}$ sınıfı için \% 70'den fazla olmalıdır. SUK ve TUK'de majör oksitlerin toplamı sırasıyla \%84 ve \%88 olduğu için, her iki uçucu kül ASTM'e göre F tipi olarak sınıflandırılmıştır. Aynı zamanda AT'nun majör oksitleri toplamı \%80'dir ve TS EN 450 standardına uygundur (Toplam majör oksit $\geq \% 70$ ). İlave olarak, AT'nun puzolanik özellikleri ve ilgili standartta tanımlanan kriterler Tablo 2'de verilmiştir. Ayrıca, mineral katkıların tane şekli ve yüzey özelliklerini belirlemek için Afyon Kocatepe Üniversitesi TAUM Laboratuarı'nda SEM görüntü çekimleri yapılmıştır. Uçucu küller genel olarak yuvarlak ve düzgün şekilli tanelerden oluşurken (Şekil 1, ortada ve sağda), andezit atık tozu keskin kenarlı düzensiz taneciklerden oluşmaktadır (Şekil 1, solda). 


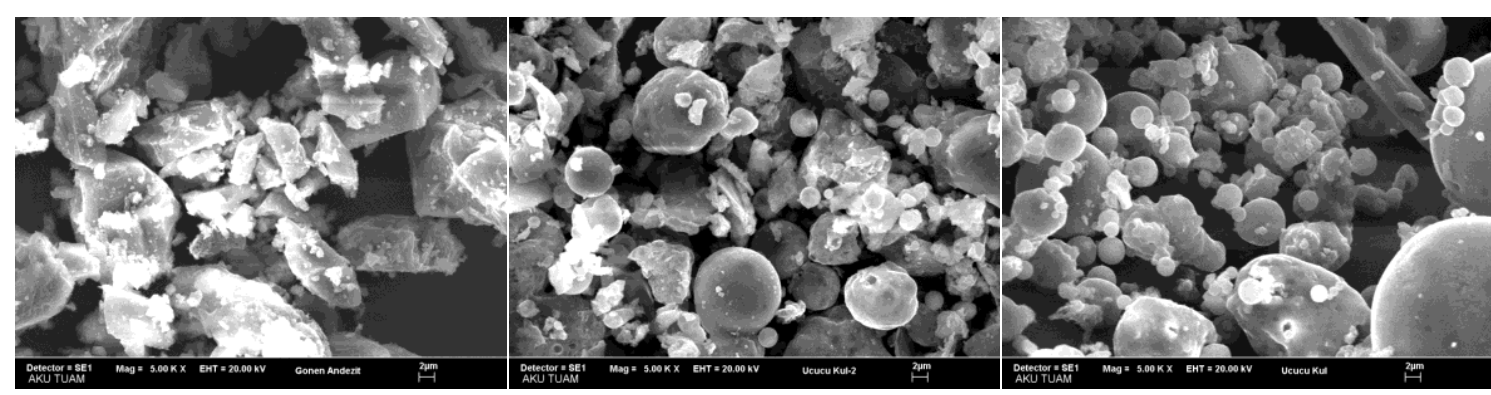

Şekil 1: AT (sol), SUK (orta) ve TUK (sağ) SEM görüntüleri

Tablo 2: AT fiziksel, kimyasal ve puzolanik özellikleri ve sınır değerler (TS EN 450-1 2006; TS EN 197-1 2012; ASTM C 618-12 2012)

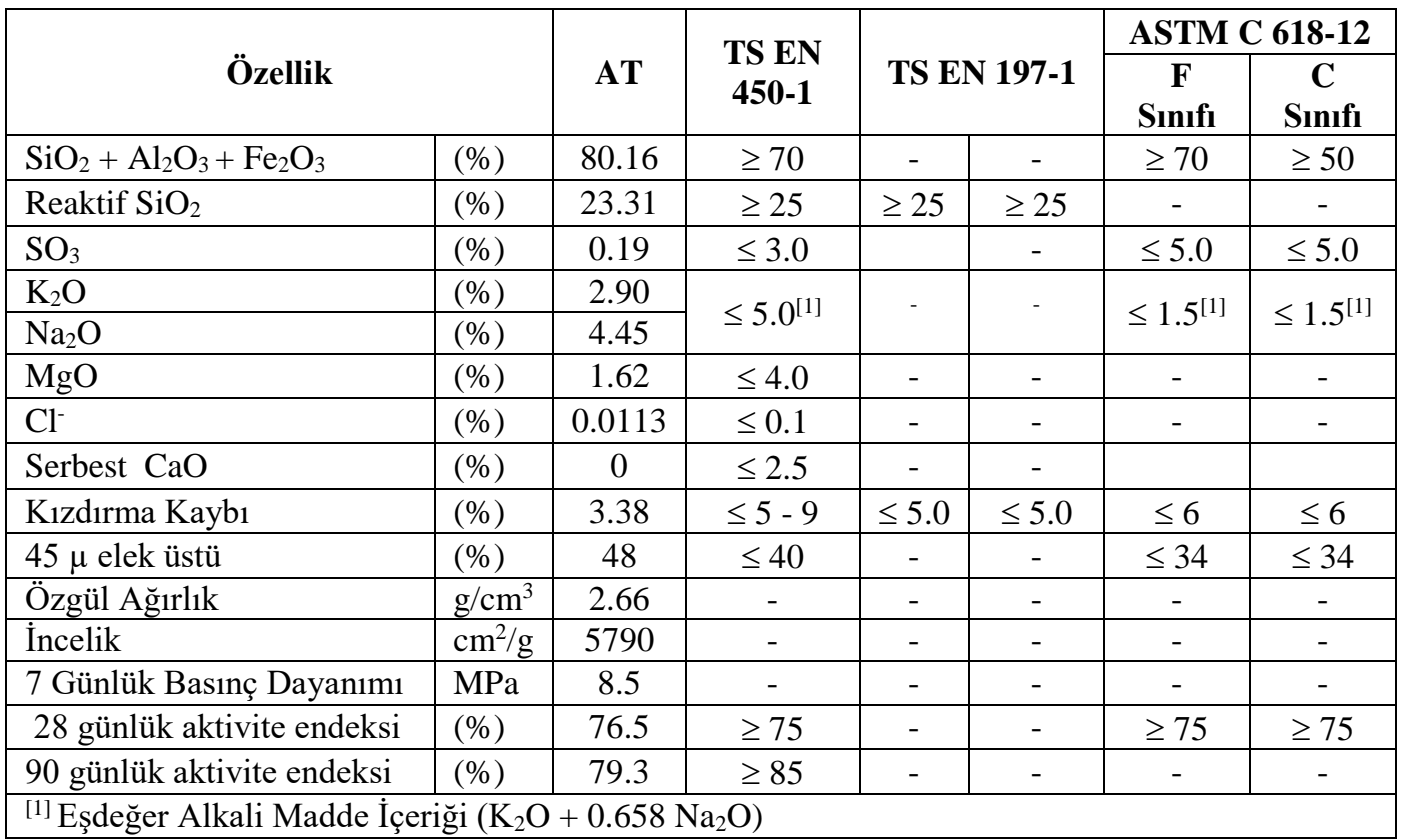

Tablo 3: Çimentonun mineralojik kompozisyonu (Göltaş AŞ. 2012)

\begin{tabular}{|c|c|}
\hline Klinker Bileșenleri & $\mathbf{( \% )}$ \\
\hline $\mathrm{C}_{3} \mathrm{~S}$ & 56.66 \\
\hline $\mathrm{C}_{2} \mathrm{~S}$ & 17.65 \\
\hline $\mathrm{C}_{3} \mathrm{~A}$ & 6.33 \\
\hline $\mathrm{C}_{4} \mathrm{AF}$ & 12.03 \\
\hline
\end{tabular}

Harç karışımlarında, özkütlesi $2.75 \mathrm{~g} / \mathrm{cm}^{3}$ ve su emmesi $\% 0.23$ olan sürekli derecelenmiş kaba agrega (4/8 ve 8/22.4 $\mathrm{mm})$ kullanılmıştır. İnce agrega özkütlesi $2.75 \mathrm{~g} / \mathrm{cm}^{3}$ ve $\% 0.52 \mathrm{su}$ emme oranında kırma kumdur. Taze betonun çökme değerlerini iyileştirmek için tüm karışımlarda özkütlesi $1.15 \mathrm{~g} / \mathrm{cm}^{3}$ ve katı içeriği \%30 olan Polikarboksilat eter tipi süper akışkanlaştıııcı kullanılmıştır.

\subsection{Karışım oranları, kürleme ve test}

İlk olarak, sabit bir çökme değeri elde etmek için $(200 \mathrm{~mm} \pm 20 \mathrm{~mm})$ bütün harç karışımlarına çökme testi uygulanmıştır. Sabit kıvam için farklı süper akışkanlaştırıcı oranları uygulanmıştır. C40/50, C55/67 ve C70/85 karışımları için çökme testine göre en uygun su/bağlayıcı oranları (s/b) sırasıyla $0.55,0.43$ ve 0.33 olarak belirlenmiștir. Bu bulgular dikkate alınarak, mineral katkıların betondaki dayanımını belirlemek için 30 farklı beton karışımı hazırlanmıştır. Beton karışım tasarımları Tablo 4'te verilmiştir. AT, SUK ve TUK mineral katkıları çimentonun ağırlıkça \%10, \%15 ve \%20'si oranlarında kullanılmıştır. 
Tablo 4: Beton karışım oranları

\begin{tabular}{|c|c|c|c|c|c|c|c|c|}
\hline \multirow{2}{*}{$\begin{array}{c}\text { Karışım } \\
\text { Adı }\end{array}$} & \multirow{2}{*}{$\begin{array}{c}\text { Çimento } \\
\left(\mathrm{kg} / \mathrm{m}^{3}\right)\end{array}$} & \multirow{2}{*}{$\begin{array}{c}\mathrm{Su} \\
\left(\mathrm{kg} / \mathrm{m}^{3}\right)\end{array}$} & \multirow{2}{*}{$\begin{array}{l}\text { Agrega } \\
\left(\mathrm{kg} / \mathrm{m}^{3}\right)\end{array}$} & \multicolumn{2}{|c|}{ Mineral Katkı } & \multirow{2}{*}{$\begin{array}{c}\text { Süper } \\
\text { Akışkanlaştırıcı } \\
\left(\mathbf{k g} / \mathbf{m}^{3}\right)\end{array}$} & \multirow{2}{*}{$\begin{array}{c}\mathrm{s} / \mathrm{b} \\
\%\end{array}$} & \multirow{2}{*}{$\begin{array}{r}\text { Slump } \\
(\mathbf{m m})\end{array}$} \\
\hline & & & & Adı & $\left(\mathrm{kg} / \mathrm{m}^{3}\right)$ & & & \\
\hline $\mathrm{C40/50}$ & 326 & 178 & 1910 & - & - & 3.26 & 0.55 & 240 \\
\hline C55/67 & 418 & 178 & 1824 & - & - & 6.28 & 0.43 & 240 \\
\hline C70/85 & 538 & 178 & 1711 & - & - & 10.76 & 0.33 & 240 \\
\hline A1-10 & 294 & 178 & 1905 & AT & 33 & 3.26 & 0.55 & 220 \\
\hline A1-15 & 277 & 178 & 1902 & AT & 49 & 3.26 & 0.55 & 220 \\
\hline A1-20 & 261 & 178 & 1900 & AT & 65 & 3.26 & 0.55 & 220 \\
\hline A2-10 & 377 & 178 & 1817 & AT & 42 & 6.28 & 0.43 & 220 \\
\hline A2-15 & 356 & 178 & 1814 & AT & 63 & 6.28 & 0.43 & 220 \\
\hline A2-20 & 335 & 178 & 1811 & AT & 84 & 6.28 & 0.43 & 220 \\
\hline A3-10 & 484 & 178 & 1702 & AT & 54 & 10.76 & 0.33 & 190 \\
\hline A3-15 & 457 & 178 & 1698 & AT & 81 & 10.76 & 0.33 & 200 \\
\hline A3-20 & 430 & 178 & 1694 & AT & 108 & 10.76 & 0.33 & 220 \\
\hline S1-10 & 294 & 178 & 1899 & SUK & 33 & 3.26 & 0.55 & 230 \\
\hline S1-15 & 277 & 178 & 1893 & SUK & 49 & 3.26 & 0.55 & 220 \\
\hline S1-20 & 261 & 178 & 1887 & SUK & 65 & 3.26 & 0.55 & 220 \\
\hline S2-10 & 377 & 178 & 1807 & SUK & 42 & 6.28 & 0.43 & 210 \\
\hline S2-15 & 356 & 178 & 1800 & SUK & 63 & 6.28 & 0.43 & 210 \\
\hline S2-20 & 335 & 178 & 1792 & SUK & 84 & 6.28 & 0.43 & 210 \\
\hline S3-10 & 484 & 178 & 1689 & SUK & 54 & 10.76 & 0.33 & 180 \\
\hline S3-15 & 457 & 178 & 1680 & SUK & 81 & 10.76 & 0.33 & 200 \\
\hline $\begin{array}{l}\text { S3-20 } \\
\end{array}$ & 430 & 178 & 1670 & SUK & 108 & 10.76 & 0.33 & 210 \\
\hline T1-10 & 294 & 178 & 1897 & TUK & 33 & 3.26 & 0.55 & 220 \\
\hline T1-15 & 277 & 178 & 1890 & TUK & 49 & 3.26 & 0.55 & 230 \\
\hline T1-20 & 261 & 178 & 1883 & TUK & 65 & 3.26 & 0.55 & 230 \\
\hline T2-10 & 377 & 178 & 1804 & TUK & 42 & 6.28 & 0.43 & 220 \\
\hline T2-15 & 356 & 178 & 1798 & TUK & 63 & 6.28 & 0.43 & 220 \\
\hline T2-20 & 335 & 178 & 1789 & TUK & 84 & 6.28 & 0.43 & 230 \\
\hline T3-10 & 484 & 178 & 1686 & TUK & 54 & 10.76 & 0.33 & 210 \\
\hline T3-15 & 457 & 178 & 1677 & TUK & 81 & 10.76 & 0.33 & 220 \\
\hline T3-20 & 430 & 178 & 1666 & TUK & 108 & 10.76 & 0.33 & 220 \\
\hline
\end{tabular}

Basınç dayanımı testi için her bir karışımdan 6 adet 150 mm’lik küp dökülmüştür. Örnekler plastik örtüyle kaplanmıştır. Beton örnekleri 24 saat sonra kalıptan çıkarılmış kür süresi boyunca kirece doygun suda bekletilmiştir. Örneklerin 28 ve 90 gün kür sürelerinde basınç dayanımları TS EN 12390-3 standardına göre belirlenmiştir (TS EN 12390-3 2010).

\section{Bulgular ve Tartışma}

Andezit atık tozu ve uçucu kül katkılı beton örneklerinin basınç dayanımları, kontrol örneklerinin dayanımları ile karşılaştırılmış ve bulgular Şekil 2, 3 ve 4'de verilmiştir. C40/50 katkısız beton (kontrol) örneklerine göre, 28 ve 90 gün kür sürelerinde ve \%10 yer değiştirme oranında en yüksek dayanım gelişimini AT ve TUK katkılı beton örnekleri göstermiştir. \%15 ve \%20 yer değiştirme oranlarında AT’lu örneklerin basınç dayanımı gelişimi SUK'lü örneklerinkine benzer ve TUK'lü örneklerinkinden düşüktür. C40/50 dayanım sınıfında, AT'lu örnekler için 28 ve 90 günde en uygun yer değiştirme oranı \%10'dur.
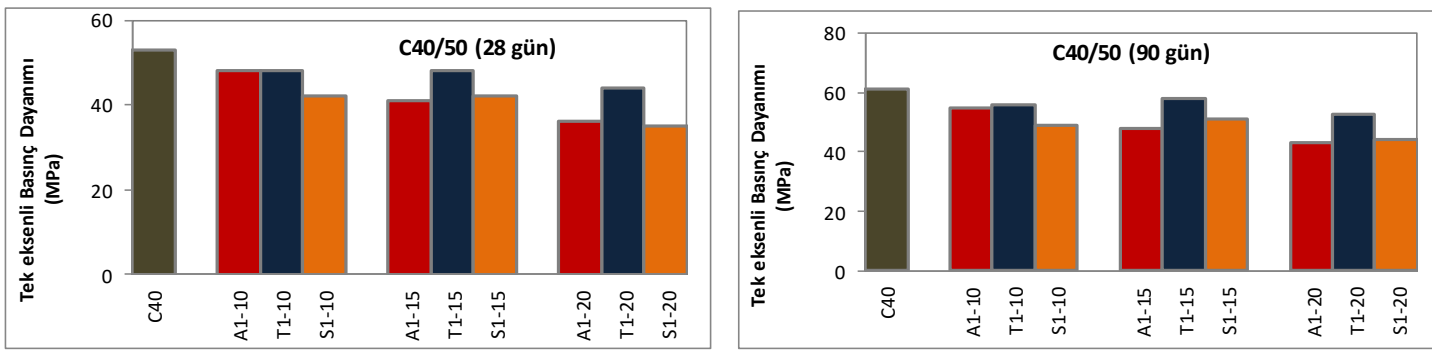

Şekil 2: C40/50 sınıfı beton örneklerinin 28 ve 90 günde basınç dayanımları 

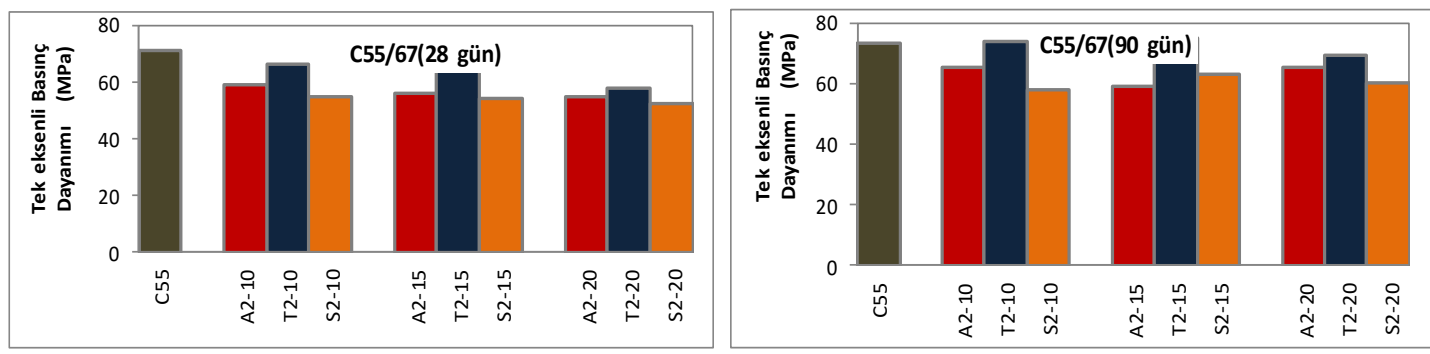

Şekil 3: C55/67 sınıfı beton örneklerinin 28 ve 90 günde basınç dayanımları

C55/67 dayanım sınıfı için 28 ve 90 gün kür süresinde $\% 10$ ve \%20 yer değiştirme oranlarında en yüksek dayanım gelişimini TUK'lü örnekler sergilemiştir. 90 günlük kür sürelerinde $\% 10$ ve $\% 20$ yer değiştirme oranları için TUK'lü örneklerin dayanımları kontrol örneklerinin dayanımlarıyla neredeyse eşittir. Genel olarak, 28 ve 90 günde, AT’lu örneklerin dayanım gelişimi SUK'lü örneklerinkinden biraz daha yüksektir. C55/67 dayanım sınıfında, AT'lu örneklerin en uygun yer değiştirme oranı 28 gün için \%10, 90 gün için $\% 10$ ve $\% 20$ dir.
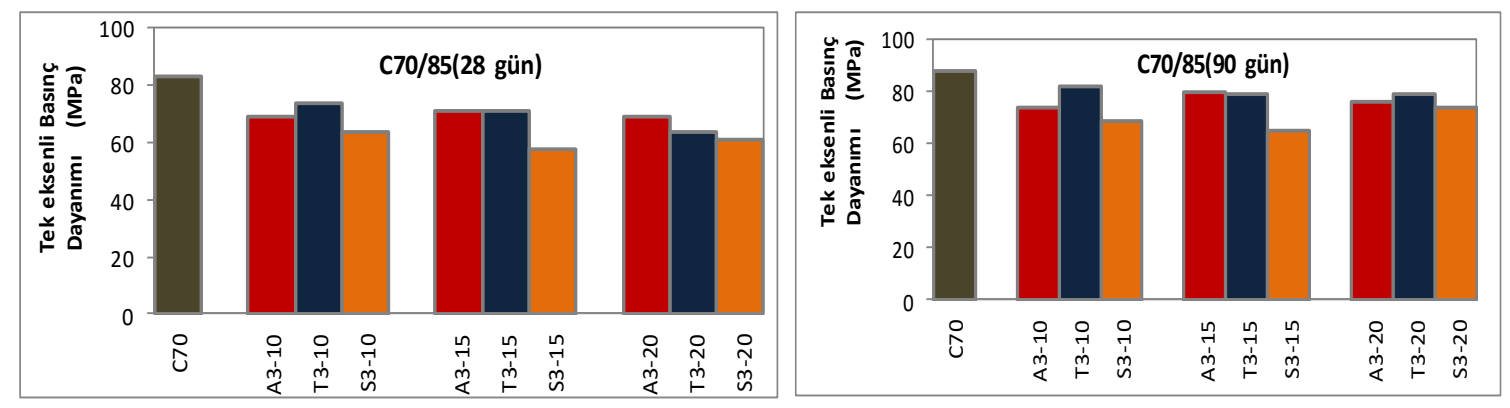

Şekil 4: C70/85 sınıfı beton örneklerinin 28 ve 90 günde basınç dayanımları

C70/85 dayanım sınıfındaki tüm mineral katkılı beton örneklerinin kontrol örneklerine göre dayanım gelişimleri yer değiştirme oranındaki artışa bağlı olarak azalmıştır. 28 ve 90 günde AT ve TUK'lü örnekler birbirine yakın dayanım gelişimleri sergilemiştir. Buna karşın SUK'lü örneklerin dayanımları diğerlerinden daha düşüktür. C70/85 dayanım sınıfında, 28 günde AT tüm yer değiştirme oranlarında benzer dayanım gelişimi sergilerken, 90 gün için en uygun yer değiştirme oranı \%15 olarak belirlenmiştir.

\section{Sonuçlar}

$\mathrm{Bu}$ çalışmada, endüstriyel atık bir malzeme olarak bol miktarda bulunan ve çevreyi kirleten andezit tozlarının beton üretiminde mineral katkı olarak kullanılabilirliği araştırılmıştır. Bu kapsamda, AT’nun beton üretiminde yaygın olarak kullanılan uçucu küllerle (TUK ve SUK) karşılaştırılabilmesi için bir kısım analiz ve deneysel çalışma yürütülmüştür. Çalışmada elde edilen sonuçlar şu şekildedir. AT fiziksel, kimyasal ve puzolanik özellikler açısından TS EN 450 ve ASTM C 618-12 standartlarında belirtilen kriterleri sağlamaktadır. AT katkılı taze betonlar ile TUK ve SUK katkılı taze betonların çökme testlerinde, birbirine oldukça yakın çökme değerleri (200-220 mm) sağlanmıştır. Bazı katkılı numuneler kontrol numunelerden elde edilen basınç değerlerini sağlamamaktadır. Bunun nedeni çimento miktarının azalması ve çimento yerine katkı kullanımıdır. Ancak katkı kullanımı nedeniyle katkılı numuneler kontrol numunelerinin basınç dayanımlarını sağlamasa da hedeflenen dayanımlarına ulaştığı belirlenmiştir. C55/67 ve C70/85 dayanım sınıflarında beton üretimi için AT'nun en uygun yer değiştirme oran $1 \% 20$ olarak belirlenmiştir. 28 ve 90 gün kür sürelerindeki etkinlik faktörleri açısından C70/85 betonunda AT katkısının en uygun kullanım oranının \%15'dir. Mineral katkı olarak en ideal yer değiştirme oranlarında AT'nun kullanımı durumunda, C40/50 betonunda yaklaşık $20 \mathrm{~kg}, \mathrm{C} 55 / 67 \mathrm{betonunda} 46 \mathrm{~kg}$, C70/85 betonunda $52 \mathrm{~kg}$ çimento tasarrufu sağlanabilir. Çalışmanın sonuçları, AT'nun beton üretiminde mineral katkısı olarak kullanımının mümkün olduğunu göstermiştir.

\section{Teşekkür}

Yazarlar çalışmaya maddi destek sağlayan Süleyman Demirel Üniversitesi Bilimsel Araştırma Projeleri Koordinasyon Birimine teşekkür ederler. 


\section{Kaynaklar}

Almeida N., Branco F., Brito J., Santos J.R., (2007a), High-performance concrete with recyled stone slurry, Cement and Concrete Research, 37, 210-220.

Almeida N., Branco F., Santos J.R., (2007b), Recyling of stone slurry in industrial activities: Application to concrete mixtures, Building and Environment, 42, 810-819.

Alyamaç K.E., İnce R., (2009), A preliminary concrete mix design for SCC with marble powders, Construction and Building Materials, 23, 1201-10.

Aruntaş H.Y., Gürü M., Dayı M., Tekin İ., (2010), Utilization of marble waste dust as an additive in cement production, Materials and Design, 31, 4039-4042.

ASTM C 125, (1994), Standard Terminology Relating to Concrete and Concrete Aggregates, Annual Book of ASTM Standards.

ASTM C 618, (1994), Standard Specification for Coal Fly Ash and Raw or Calcined Natural Pozzolana for Use as a Mineral Admixture in Portland Cement Concrete, Annual Book of ASTM Standards.

ASTM C 618-12, (2012), Standard Specification for Coal Fly Ash and Raw or Calcined Natural Pozzolan for Use in Concrete, West Conshohocken, ASTM International. PA.

Aydın A.C., Gül R., (2012), Influence of volcanic originated natural materials as additives on the setting time and some mechanical properties of concrete, Construction and Building Materials, 21, 1277-1281.

Belaidi A.S.E., Azzouz L., Kenai S., (2012), Effect of natural pozzolana and marble powder on the properties of self-compacting concrete, Construction and Building Materials, 31, 251-257.

Corinaldesi V., Moriconi G., Naik T.R., (2010), Characterization of marble powder for its use in mortar and concrete, Construction and Building Materials, 24, 113-117.

Erdoğan T.Y., (2007), Beton, METU Press, Ankara, Türkiye, 760ss.

Ergün A., (2011), Effect of the usage of diatomite and waste marble powder as partial replacement of cement on the mechanical properties of concrete, Construction and Building Materials, 25, 806-812.

Gencel O., Özel C., Köksal F., Erdoğmuş E., Martinez-Barrera G., Brostow W., (2012), Properties of concrete paving blocks made with waste marble, Journal of Cleaner Production, 21, 62-70.

Gesoğlu M., Güneyisi E., Kocabağ M.E., Bayram V., Mermerdaş K., (2012), Fresh and hardened characteristics of self-compacting concretes made with combined use of marble powder, limestone filler, and fly ash, Construction and Building Materials, 37, 160170.

Göltaş A.Ş., (2012), Montly (September) quality report of cement, Isparta, Türkiye.

Hamidi M., Kacimi L., Cyr M., Clastres P., (2013), Evaluation and improvement of pozzolanic activity of andesite for its use in ecoefficient cement, Construction and Building Materials, 47, 1268-1277.

Jain N., (2012), Effect of nonpozzolanic and pozzolanic mineral admixtures on the hydration behavior of ordinary Portland cement, Construction and Building Materials, 27, 39-44.

Karakuş A., (2011), Investigation on possible use of Diyarbakir basalt waste in Stone Mastic Asphalt, Construction and Building Materials, 25, 3502-07.

Sarışık A., Sarışık G., Sentürk A., (2011), Applications of glaze and decor on dimensioned andesites used in construction sector, Construction and Building Materials, 25, 3694-702.

Soğancığlu M., Yel E., Y1lmaz-Kesin U.S., (2013), Utilization of andesite processing wastewater treatment sludge as admixture in conctere mix, Construction and Building Materials, 46, 150-155.

Topçu İ.B., Bilir T., Uygunoğlu T., (2009), Effect of waste marble dust content as filler on properties of self-compacting concrete, Construction and Building Materials, 23, 1947-1953.

TS EN 12390-3, (2010), Beton-Sertleşmiş Beton Deneyleri-Bölüm 3. Deney numunelerinde basınç dayanımının tayini, Türk Standartları Enstitüsü, Ankara, Türkiye.

TS EN 197-1, (2012), Çimento, Türk Standartları Enstitüsü, Ankara, Türkiye.

TS EN 450-1, (2006), Uçucu kül-Betonda kullanılan, Türk Standartları Enstitüsü, Ankara, Türkiye.

Uysal M., Sümer M., (2011), Performance of self-compacting concrete containing different mineral admixtures, Construction and Building Materials, 25, 4112-4120.

Uysal M., Yilmaz K., (2011), Effect of mineral admixtures on properties of self-compacting concrete, Cement and Concrete Composites, 33, 771-776. 